Archimedes

\title{
The wisdom of Archimedes
}

\section{B Phillips}

\section{A valuable concept}

A rchimedes, the bimonthly evidence based clinical question section of Archives of Diseases in Childhood, was first published in September 2001. Over the three years since it began, it has asked clinical questions as diverse as "Does giving albumin infusion in hypoalbuminaemic children with oncological disease affect colloid osmotic pressure and outcome?" and "Is chiropractic an effective treatment in infantile colic?". Archimedes has been the subject of debate ${ }^{1}$ and research, ${ }^{2}$ and continues to fuel argument from practising clinicians. ${ }^{34}$

What Archimedes is, where it came from, and what it isn't, are all questions which must be answered to explain the value of Archimedes. How it can be made better-more usable, more readable, and more relevant-are also points which must be explained.

\section{WHAT IS ARCHIMEDES?}

Archimedes is a collection of topic summaries and critical appraisal notes. The topic reports provide 'evidence based' answers to common questions which are not at the forefront of research but are at the core of practice.

Archimedes sets out a clear and transparent path from the clinical question asked to the clinical bottom lines concluded. It enables readers to take a readable digest of the relevant evidence and use this to reflect on their own clinical practice. It also provides a model of the steps of evidence based practice for clinicians to attempt to follow when asking questions themselves. In this latter aspect, the critical appraisal notes are intended to integrate with the topic summaries and illuminate an aspect of the evidence based practice process.

Archimedes topic reports are submitted to the journal by clinicians who then receive a series of peer reviews upon their work, addressing the critical appraisal and clinical content of the reports. The reports are also reviewed by the Editor in Chief who makes a final decision about publication.

The topic reports are across the spectrum of paediatric practice and always provide the 'best evidence possible' to answer clinical questions. The topic reports have critically addressed the results of prior systematic reviews (for example, Srinivasan and Arora ${ }^{5}$ ), added further studies to the evidence they contain, and provided a critical reflection on the conclusions drawn. The act of appraising systematic reviews, even from the Cochrane Collaboration, is essential: not all Cochrane reviews are of the same standard, as many readers will have been disappointed to learn.

\section{WHERE IS ARCHIMEDES FROM?}

Archimedes' topic summaries are adapted from a format which has been successfully developed by Kevin Macaway-Jones and the group at the Emergency Medicine Journal- "BestBets". These themselves in turn were developed from the "critically appraised topics" of the Centre for Evidence Based Medicine at Oxford. Similar projects are to be found in the Interactive Journal of Cardiothoracic Surgery and the ATTRACT project from Wales.

All these sources take as their root the five step model of evidence based practice developed by the Centre for Evidence Based Medicine at Oxford: ask a (clinical) question, acquire (relevant) information, appraise that evidence, apply it in practice, and assess one's performance. Archimedes addresses the first four steps in print (but the author has had the pleasure of assessing their own performance during the peer review process-in this way Archimedes is an educational experience as well as a service to practising clinicians).

\section{WHAT IS IT NOT?}

The topic reports in Archimedes do not attempt to be traditional systematic reviews, though they are as exhaustive as a practising clinician can produce in a short turnaround time, and have searches as comprehensive as some systematic reviews (cf. van Rijn et al and Narchi ${ }^{7}$ ). They make no attempt to statistically aggregate the data, and little to search the grey, unpublished literature. They do not address every aspect of the management of a condition, unlike guidelines. And they don't provide new data from primary research. What Archimedes topic summaries offer are practical, best evidence based answers to practical, clinical questions. The philosophical stance of Archimedes is taken not from the Greeks, but from Voltaire:

"Let not the best be the enemy of the good." (Voltaire)

\section{IS THIS A GOOD THING?}

We know quite a lot about how clinicians ask questions and gain information. It has been found that expert opinions are often wrong, ${ }^{8}$ that editorials and commentaries are read more often than primary research, ${ }^{9}$ and that clinical questions are asked more often than answered..$^{10}{ }^{11}$ It's clear that stories influence people more than data do. ${ }^{12}$

Archimedes topic summaries try to address these issues. Each summary tells a story which asks and then answers a structured clinical question. It clearly defines its information sources and tries not to rely on expert opinion. As different people make different judgements, the same data can lead to different clinical conclusions. The Archimedes format makes the translation of evidence into recommendation transparent, in a way that traditional reviews do not.

The big brother of Archimedes, BestBets, has been acknowledged by the Faculty of Accident and Emergency Medicine as a useful source of continuing medical education. Completing topic reports allows the author to claim credit up to the maximum available for publications. The journal's readership survey indicates the BestBets section is the most popular aspect of the publication. ${ }^{13}$ A similar question answering project in Wales (ATTRACT) was found to be extremely popular with GPs ${ }^{14}$ and clinically accurate.

\section{MAKING IT BETTER}

There are areas that Archimedes does not currently do well. The search strategies have been published without dates-given the delays between submission, acceptance, and publication, this can produce clinically important differences in the accuracy of the information when it arrives on your doorstep. All Archimedes topic reports should now have the search date attached. As with all published sources of information, the topic reports go "out of date", and despite best intentions are not always updated; a problem Archimedes shares with nearly all sources of evidence. While researching and writing this commentary, it has emerged that the clinical bottom lines can be misleadingly bold when there is limited evidence. New topics provide "grades of recommendation" alongside the statements they make. 


\section{CLINICAL BOTTOM LINES}

Archimedes provides clinicians with "evidence based" answers to common questions which are not at the forefront of research but are at the core of practice, and supports the reader in expanding their knowledge of critical appraisal. The topic reviews provide a more transparent review of clinical information than the discussion sections of primary research articles or the commentaries at the front of Archives. It provides digests which are more readable and relevant than most systematic reviews. We should not "let the best be the enemy of the good" and should allow Archimedes to provide a balance of clinical relevance with academic integrity.

\section{ACKNOWLEDGEMENTS}

Thanks to Prof. Paul Glazsiou, Prof. David Sackett, Simon Carley, Prof. Kevin MacawayJones, and Jon Brassey.
Arch Dis Child 2006;91:95-96.

doi: 10.1136/adc.2004.064287

Correspondence to: Dr Bob Phillips, Evidencebased On Call, Centre for Evidence-based Medicine, University Dept of Psychiatry Warneford Hospital, Headington OX3 7JX, UK; bob.phillips@doctors.org.uk

Competing interests: Bob Phillips is the Section Editor of Archimedes and receives an annual honorarium from BMJPG for this work. He also works voluntarily as a web editor for BestBets

\section{REFERENCES}

1 Lopez T. On Archimedes. Arch Dis Child 2003:88:176-7.

2 Rudolf M, Rowland G, Das G, et al. What's the use of Archimedes? Arch Dis Child 2002;87:168-9.

3 Brand PLP. What is the normal range of blood glucose concentration in healthy term newborns? Arch Dis Child Fetal Neonatal Ed 2004;89:F375

4 Baumer JH. Archimedes vs Cochrane. adc.bmijournals. com/cgi/eletters/89/1/ 82\#992, 9 Jul, 2004.
5 Srinivasan R, Arora RS. Do well infants born with an isolated single umbilical artery need investigation? Arch Dis Child 2005:90:100-1.

6 van Rijn JCW, Grote FK, Oostdijk W, et al. Short stature and the probability of coeliac disease, in the absence of gastrointestinal symptoms. Arch Dis Child 2004;89:882-3.

7 Narchi H. Risk of Wilms' tumour with multicystic kidney disease: a systematic review. Arch Dis Child 2005;90:147-9.

8 Antman EM, Lau J, Kupelnick B, et al. A comparison of the results of meta-analyses of RCTs and recommendations of clinical experts. JAMA 1992;268:240-8.

9 Loke YK, Derry S. Does anybody read "evidencebased" articles? BMC Med Res Methodol 2003;3:14.

10 Green ML, Ciampi MA, Ellis PJ. Residents' medical information needs in clinic: are they being met? Am J Med 2000;109:218-23.

11 Bergus GR, Randall CS, Sinift SD, et al. Does the structure of clinical questions affect the outcome of curbside consultations with specialty colleagues? Arch Fam Med 2000;9:541-7.

12 Newman TB. The power of stories over statistics. BMJ 2003:327:1424-7.

13 Macaway-Jones K, Wardropp J, Driscoll P. BetsBets. Emerg Med J 2004;21:523.

14 Brassey J, Elwyn G, Price C, et al. Just in time information for clinicians: a questionnaire evaluation of the ATTRACT project. BMU 2001;322:529-30.

\section{Complementary and alternative medicine for children: a good or a bad thing?}

\section{E Ernst}

\section{Commentary on the paper by Cincotta et al (see page 153)}

u this issue, Cincotta et al compare the usage of complementary and alternative medicine (CAM) in Cardiff (UK) with that of Melbourne (Australia). ${ }^{1}$ The authors note that it is remarkably high in both places and that a number of intriguing differences exist between the two locations. They explain these through a range of sociocultural differences. Perhaps the most obvious of these is availability, and Cincotta provide data to support this hypothesis. In a circular fashion, usage seems to determine the number of CAM practitioners which, in turn, determines usage.

In addition to these factors, there could well be others. We have, for instance, shown a striking correlation between the sales figures for BMW cars and those for CAM products. ${ }^{2}$ This suggests that affluence affects CAM usage-not altogether implausible as CAM is largely private medicine. The "undue influence of the press" ${ }^{\prime 3}$ is also noteworthy. The UK daily press depicts CAM in a significantly more positive light than conventional medicine ${ }^{4}$ and many of the $\sim 40$ million (!) websites on CAM are overtly promotional and dangerously misleading. ${ }^{5}$ What is perhaps worse, a UK government sponsored guide $^{6}$ is hardly any better (table 1 ).

The high prevalence of CAM is clearly a two edged sword. If the benefit of any given CAM therapy outweighs its risk, its use is likely to be a good thing for children. Sadly there are only very few treatments for which this is demonstrably true. ${ }^{7}$ For the vast majority of interventions, we cannot be sureeither because the evidence does not exist at all or because it is inconclusive. ${ }^{7}$ For a few treatments, however, we can say with some confidence that the riskbenefit balance is negative. ${ }^{7}$ Examples for these three categories are provided in table 2 .

Cincotta et al also show that the most popular CAM treatments include vitamins, herbal medicines, and dietary supplements. It is noteworthy that the evidence for these approaches is very

Table 1 Selected statements from a recent patient guide*

\begin{tabular}{|c|c|}
\hline Statement (quote) ${ }^{6}$ & Evidence $^{7}$ \\
\hline $\begin{array}{l}\text { "...the risk of a stroke [after upper spinal manipulation] is between } 1 \text { and } 3 \\
\text { million manipulations" } \\
\text { "Acupuncture is being increasingly used for people trying to overcome } \\
\text { addictions..." } \\
\text { "Craniosacral therapists treat a wide range of conditions from acute to } \\
\text { chronic health problems..." } \\
\text { "Healing is used for a wide range of ... conditions. Research has shown } \\
\text { benefit in many areas, including healing of wounds, ... migraine or irritable } \\
\text { bowel syndrome..." }\end{array}$ & $\begin{array}{l}\text { Due to extreme under-reporting the risk is undefined } \\
\text { All systematic reviews fail to show efficacy of acupuncture for this indication } \\
\text { There is no trial evidence at all to suggest that craniosacral therapy is effective } \\
\text { The best evidence available to date fails to show effects beyond a placebo } \\
\text { response }\end{array}$ \\
\hline
\end{tabular}

"The stated aim of the guide 6 was "to give you [the patient] enough information to help you choose a complementary therapy that is right for you". 